\title{
Polysaccharides obtained from mycelia of Cordyceps militaris attenuated doxorubicin-induced cytotoxic effects in chemotherapy
}

\author{
Ruo-Kai Lin ${ }^{1,2}$, Chen-Yen Choong ${ }^{3,4}$, Wei-Hsuan Hsu', Chen-Jei Tai ${ }^{3,4,6,7}$, \\ Cheng-Jeng Tai ${ }^{8,9}$
}

1. Master Program for Clinical Pharmacogenomics and Pharmacoproteomics, Taipei Medical University, Taipei, Taiwan.

2. Graduate Institute of Pharmacognosy, Ph.D. Program for the Clinical Drug Discovery from Botanical Herbs, Taipei Medical University, Taipei, Taiwan.

3. Graduate Institute of Clinical Medicine, College of Medicine, Taipei Medical University, Taipei, Taiwan.

4. Department of Obstetrics and Gynecology, School of Medicine, College of Medicine, Taipei Medical University, Taipei, Taiwan

5. Biochemical Process Technology Department, Center of Excellence for Drug Development, Biomedical Technology and Device Research Laboratories, Industrial Technology Research Institute, Hsinchu, Taiwan

6. Department of Traditional Chinese Medicine, Department of Internal Medicine, Taipei Medical University Hospital, Taipei, Taiwan

7. Traditional Herbal Medicine Research Center, Taipei Medical University Hospital, Taipei, Taiwan

8. Division of Hematology and Oncology, Department of Internal Medicine, Taipei Medical University Hospital, Taipei, Taiwan.

9. Division of Hematology and Oncology, Department of Internal Medicine, School of Medicine, College of Medicine, Taipei Medical University, Taipei, Taiwan.

\begin{abstract}
Objectives: Fungus Cordyceps militaris has been used as a herbal tonic in traditional Chinese medicine, which could be surface liquid-cultured for mycelia production. To evaluate the potential of polysaccharides obtained from mycelia of Cordyceps militaris (PS-MCM) for attenuation of side-effects of chemotherapy.

Methods: Doxorubicin was used to induce cytotoxicity in THP-1 monocytes and EL-4 T cells, and the effects of PS-MCM on cell viability and cytokine production were detected on doxorubicin-treated THP-1 and EL-4 cells.

Results: PS-MCM reduced doxorubicin-induced cell death and promoted cell proliferation in THP-1 and EL-4 cells. Moreover, PS-MCM elevated the level of cytokines associated with immune-modulation of THP-1 and EL-4 cells.

Conclusion: These findings indicate that PS-MCM has potential for development as a functional food to counteract side effects of chemotherapy.
\end{abstract}

Keywords: Cordyceps militaris, traditional Chinese medicine, doxorubicin, chemotherapy, immunotherapy.

DOI: https://dx.doi.org/10.4314/ahs.v19i2.40

Cite as: Lin R-K, Choong C-Y, Hsu W-H, Tai C-J, Tai C-J. Polysaccharides obtained from mycelia of Cordyceps militaris attenuated doxorubicin-induced cytotoxic effects in chemotherapy. Afri Health Sci.2019;19(2): 2156-2163. bttps:/ / dx.doi.org/10.4314/ abs.v19i2.40

\section{Corresponding author: \\ Cheng-Jeng Tai, \\ Division of Hematology and Oncology, \\ Department of Internal Medicine, \\ Taipei Medical University Hospital, \\ Taipei, Taiwan. \\ 252 Wu Hsing Street, Taipei, Taiwan 110 \\ Email: cjtai@tmu.edu.tw}

\section{Introduction}

Combined immunotherapy and chemotherapy is one of the most efficient strategies for treating cancer. It is important to design an effective treatment program which can optimize immunotherapy and chemotherapy to diminish side effects. ${ }^{1}$ Clinical evidence shows that eliminating cancer via the immune system is promising and will propel more research in immunotherapy. Therefore, many studies have been done to use the most appropriate
Health Sciences

2156
(C) 2019 Lin et al. Licensee African Health Sciences. This is an Open Access article distributed under the terms of the Creative commons Attribution License (https://creativecommons.org/licenses/BY/4.0), which permits unrestricted use, distribution, and reproduction in any medium, provided the original work is properly cited. 
strategies to meet different performance objectives. The use of complementary and alternative medicine has become a popular option to support the conventional therapy in many areas. ${ }^{2-4}$ For example, many herbal formulas and remedies based on the traditional Chinese medicine are well accepted among cancer patients with Chinese background..$^{5-7}$

The fungus Cordyceps has been used as a herbal tonic in traditional Chinese medicine for over 300 years. Numerous studies have recently reported the anticancer activity of C. sinensis, against B16 melanoma, ${ }^{8}$ leukemia, ${ }^{9}$ thyroid carcinoma, ${ }^{10}$ hepatocellular carcinoma, ${ }^{11}$ and renal cancer cells. ${ }^{12}$ Cordycepin is a crucial bioactive compound derived from C. militaris. The inhibitory effect of cordycepin on cancer was diminished by adenosine deaminase catalysis in vivo. ${ }^{13}$ We have demonstrated the anti-oral cancer activity of water extract isolated from the mycelia of surface liquid-cultured C. militaris. ${ }^{14}$ In addition, polysaccharides were isolated from the mycelium of submerged-fermented $C$. militaris by liquid static culture, ${ }^{15}$ which have been shown to stimulate immune activity via promotion of lymphatic spleen cell proliferation and cytokines production. ${ }^{16}$

The chemotherapeutic drug doxorubicin has been found to cause cell toxicity of normal immunocytes during chemotherapy, leading to loss of immune activity and other side-effects. Moreover, a healthy immune system was deemed irrelevant for treating cancer in the context of chemotherapy. ${ }^{17}$ The immune cells interact with the cancer cells and the immune system is fully capable of killing tumor cells. However, immune cells have trouble to recognizinge them due to tumor-induced immune suppression. ${ }^{18}$ Evidence from a recent study has shown that immune-stimulatory activity mediated by herbs could attenuate side-effects caused by chemotherapy. ${ }^{19}$ Therefore, the aim of this study was to evaluate the potential of polysaccharides obtained from the mycelia of surface liquid-cultured C. militaris (PS-MCM) on immune-stimulatory activity against side-effects of chemotherapy.

\section{Materials and methods}

\section{Sample isolation}

C. militaris (BCRC34380) was obtained from the Bioresource Collection and Research Center (Hsinchu, Taiwan).The liquid seed culture was inoculated with a mycelium mat from a stock slant and cultured in a $500 \mathrm{~mL}$ conical flask containing $200 \mathrm{~mL}$ of the medium $(10 \mathrm{~g} / \mathrm{L}$ peptone, $30 \mathrm{~g} / \mathrm{L}$ glucose, $0.5 \mathrm{~g} / \mathrm{LMgSO} 4,0.5 \mathrm{~g} / \mathrm{L} \mathrm{K} 2 \mathrm{H}-$ $\mathrm{PO} 4$, and $0.5 \mathrm{~g} / \mathrm{L} \mathrm{KH} 2 \mathrm{PO} 4)$ at $25^{\circ} \mathrm{C}$ on a rotary shaker at $150 \mathrm{rpm}$ for 7 days for maintenance. The cultured mycelia were collected and freeze dried, and the mycelium powder was dissolved in water and heated for 60 minutes at $60^{\circ} \mathrm{C}$ to extract intracellular polysaccharides by alcohol precipitation.

\section{Cell culture}

THP-1, a human monocytic leukemia cell line, was obtained from the Bioresource Collection and Research Center (BCRC 60430; Food Industry Research and Development Institute, Hsinchu, Taiwan). Cells were maintained in RPMI1640medium supplemented with 10\% FBS, streptomycin $(100 \mathrm{mg} / \mathrm{mL})$, penicillin $(100 \mathrm{U} / \mathrm{mL})$, $50 \mu \mathrm{M} \beta$-mercaptoethanol, and $5.5 \mathrm{mM}$ D-glucose in a $5 \%$ CO2 incubator at 37oC. EL-4 murine T-lymphoma cells were purchased from the Bioresource Collection and Research Center (Hsinchu, Taiwan). EL-4 cells were cultured in RPMI-1640 medium supplemented with 10\% heat-inactivated FBS. Confluent cells were sub-cultured at a ratio of $1: 3$ in a $10 \mathrm{~cm}$ dish, and media were changed twice a week. Cells were cultured at $37^{\circ} \mathrm{C}$ in a humidified atmosphere of $5 \% \mathrm{CO} 2$.

\section{Cell viability}

THP-1 and EL-4 cells were treated by doxorubicin with various polysaccharides obtained from the mycelia of surface liquid-cultured C. militaris (PS-MCM) for 24 hours. Cell viability was measured using the MTT reduction assay. Incubation was terminated by media aspiration and addition of $5 \mathrm{mg} / \mathrm{mL}$ of MTT working solution to each well. Formazane formation was terminated after 3 hours by removal of the MT'T solution. Subsequently, appropriate amounts of DMSO were added to each well to solubilize the formazane. The formazane-containing samples were transferred to a new 96-well plate and the absorbance at $590 \mathrm{~nm}$ was measured with a spectrophotometer (U-2000, Hitachi, Tokyo, Japan). ${ }^{20,21}$

\section{Cytokines assay}

Quantification of cytokines was carried out by ELISA kits. After 24 hours of incubation, the culture medium of control and treated cells was collected, centrifuged, and stored at $-80^{\circ} \mathrm{C}$ until tested. The levels of interleukin (IL)-1beta, tumor necrosis factor (TNF)-alpha, interferon (IFN)-gamma, IL-6, and IL-4 released into culture medi- 
um were determined with ELISA kits from eBioscience (San Diego, CA, USA).

\section{Statistical analysis}

Experimental results were analyzed in triplicates and expressed as means \pm standard deviation (SD). The results were subjected to one-way analysis of variance (ANOVA) and Duncan's multiple range tests and the significance of differences between sample means was calculated; and $\mathrm{p} \leq 0.05$ was considered significant.

\section{Results}

Effect of PS-MCM on cell viability of THP-1 monocytes The data showed that biomass of mycelium from C. militaris was significantly increased in porcine liver extracts medium when compared with the basal medium or the de-fat soybean extracts medium by surface liquid cultivation (Supplemental Figure 1A). Moreover, we evaluated polysaccharides production of surface liquid-cultured $C$. militaris by different substrates, including polysaccharides obtained from mycelia of $C$. militaris grown in basal medium, polysaccharides obtained from mycelia of C. militaris grown in porcine liver extracts medium, and polysaccharides obtained from mycelia of $C$. militaris grown in defat soybean medium. Results are shown in Supplemental Figure 1B. The ability of polysaccharide production by C. militaris was greater in basal medium than porcine liver extracts medium and de-fat soybean medium, revealing that protein and nitrogen resource may suppress the production of polysaccharides. There were no significant differences in DPPH and ABTS free radicals scavenging activity, and chelating activity among the groups (Supplemental Figure 2A and 2B).

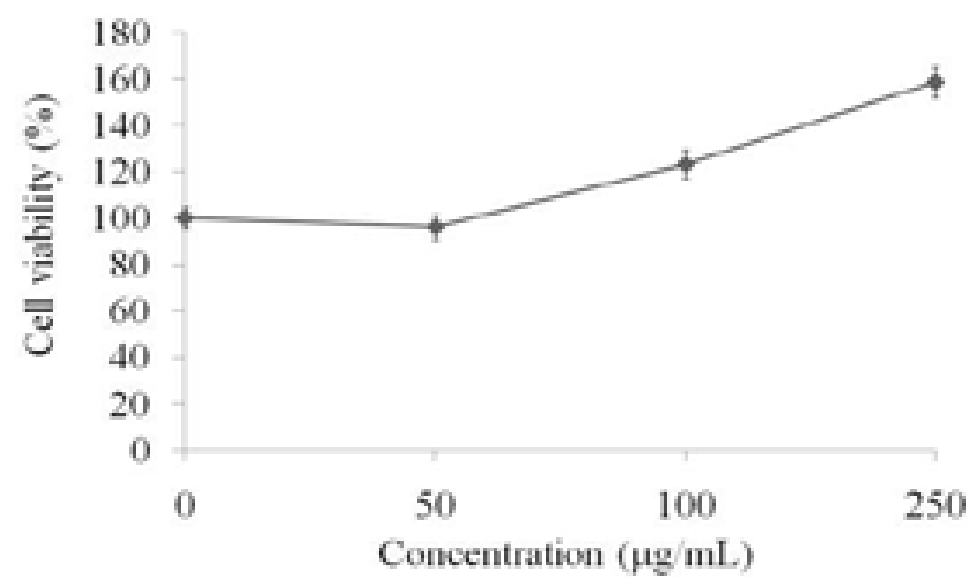

Figure 1. Effects of PS-MCM on cell proliferation in THP-1 cells for $24 \mathrm{~h}$.. Results are expressed as mean $\pm \mathrm{SD}(\mathrm{n}=3)$

The THP-1 monocytes were treated with various doses $(50,100$, and $250 \mu \mathrm{g} / \mathrm{mL})$ of PS-MCM isolated from mycelia of C. militaris grown in basal medium for 24 hoursand the cell viability were determined by MTT assay. The results showed that BM PS-MCM promoted cell proliferation of THP-1 monocytes in a dose-dependent manner (Figure 1).

Doxorubicin is a drug used in chemotherapy. The THP1 monocytes were treated with various doses of doxo- rubicin for 24 hours, and cell viability was measured by MT'T assay. As shown in Figure 2, when compared to the control group, doxorubicin $(0.5,1,2.5$, and $5 \mu \mathrm{M}$, respectively) treatment significantly resulted in cell toxicity in THP-1 monocytes, and the cell viabilities were 95.8, 74.9, 61.3 , and $23.9 \%$, respectively. Some $2.5 \mu \mathrm{M}$ of doxorubicin was used to induce cell toxicity for suppressing immune activity of the cells, and the protective effects of PS-MCM on doxorubicin-treated THP-1 monocytes against side effects in chemotherapy were investigated. 


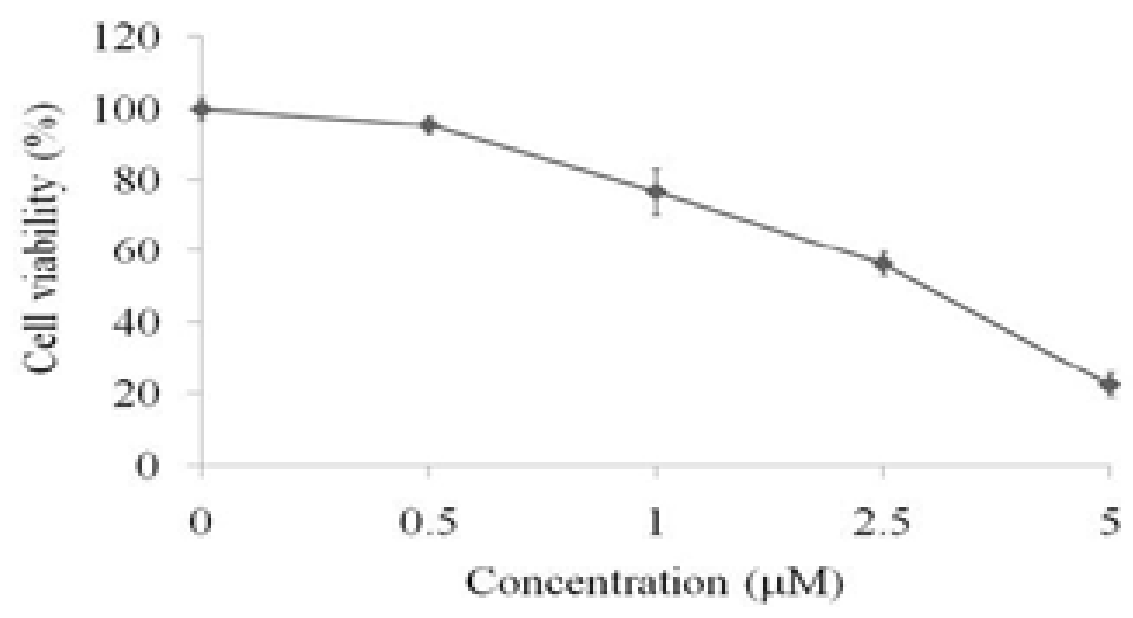

Figure 2. Inhibitory effects of doxorubicin on cell viability of THP-1 cells for $24 \mathrm{~h}$. Results are expressed as mean $\pm \operatorname{SD}(n=3)$

As shown in Figure 3, when compared with the blank group, PS-MCM treatment significantly increased the cell proliferation of THP-1 monocytes, whereas $2.5 \mu \mathrm{M}$ of doxorubicin treatment markedly decreased cell viabili- ty. Moreover, PS-MCM treatment attenuated doxorubicin-induced toxic effects in THP-1 monocytes.

Effects of PS-MCM on immune regulation in doxorubicin-treated THP-1 monocytes

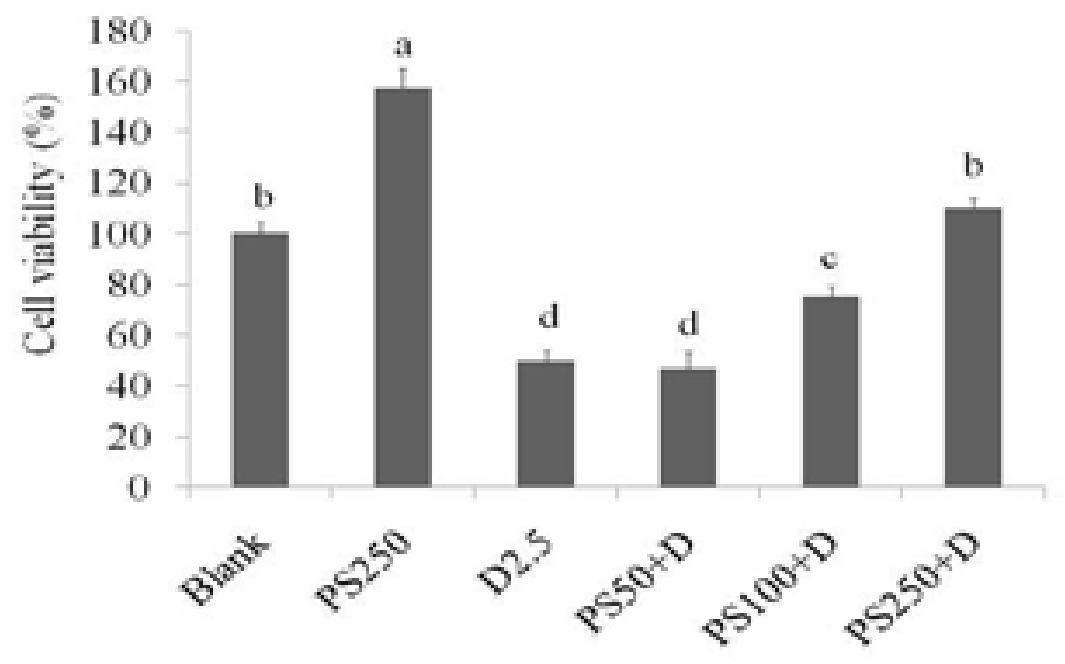

Figure 3. Effects PS-MCM combined with doxorubicin on cell viability of THP-1 cells for $24 \mathrm{~h}$. Results are expressed as mean $\pm \operatorname{SD}(n=3)$.

Significant difference was shown by different letters $(\mathrm{p}<0.05)$. PS: PSMCM; D: doxorubicin. 
The levels of IL-1beta, TNF-alpha, IFN-gamma, and IL-6 were detected after treating with PS-MCM or/ and doxorubicin in THP-1 monocytes. The results displayed in Table 1 show that, $250 \mu \mathrm{g} / \mathrm{mL}$ of PS-MCM treatment efficiently promoted the production of cytokines in THP-1 monocytes when compared to the blank group. Reciprocal results were obtained with doxorubicin treatment. None the less, treating with PS-MCM potentially reversed the immune-stimulatory activity in doxo- rubicin-induced THP-1 monocytes for the generation of L-1beta, TNF-alpha, IFN-gamma, and IL-6.

\section{Effect of PS-MCM on cell viability of EL-4 T cells}

The EL-4 T cells were treated with various doses (50, 100 , and $250 \mu \mathrm{g} / \mathrm{mL}$ ) of PS-MCM for 24 hours and the cell viability were determined by MT'T assay. The results indicated that PS-MCM promoted cell proliferation of EL-4 T cells in a dose-dependent manner (Figure 4).

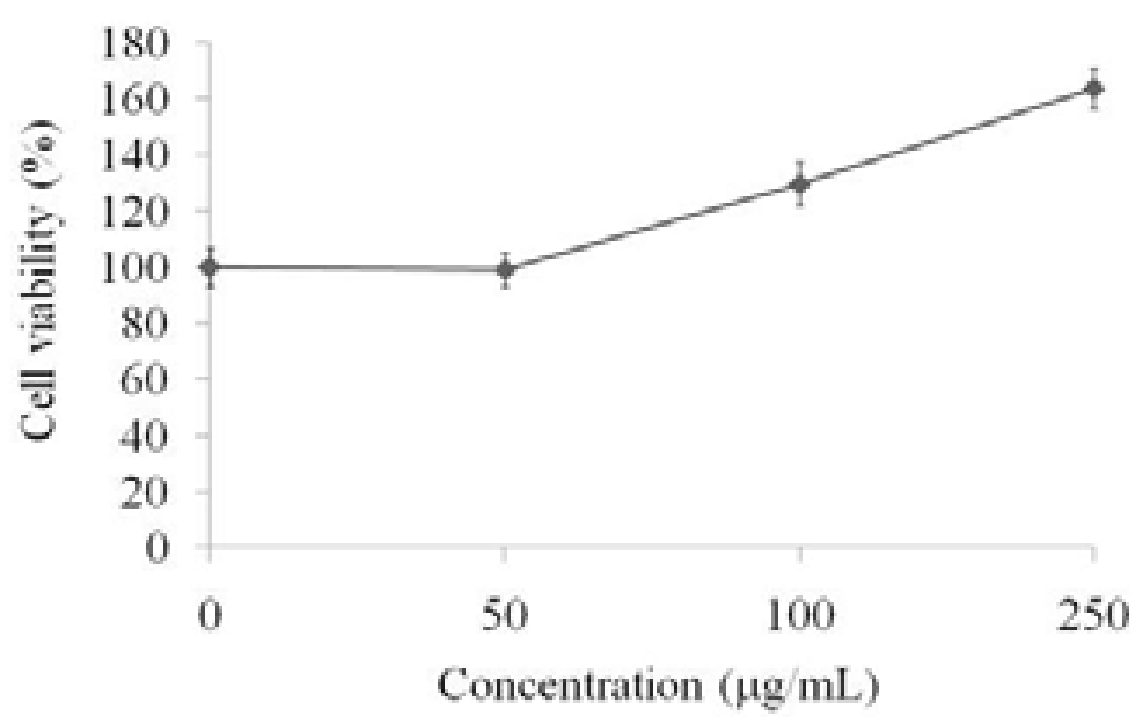

Figure 4. Effects of PS-MCM on cell proliferation of EL-4 cells for $24 \mathrm{~h}$. Results are expressed as mean \pm SD $(n=3)$. PS: PSMCM; D: doxorubicin

In addition, The EL-4 T cells were treated with various doses of doxorubicin for 24 hours, and the cell viability was measured by MTT assay. As shown in Figure 5, when compared with the control group, doxorubicin significantly caused cell toxicity in EL-4 T cells. Some $2.5 \mu \mathrm{M}$ of doxorubicin was used to induce cell toxicity for suppressing immune activity of the cells, and the protective effects of PS-MCM on doxorubicin-treated EL-4 T cells against side effects in chemotherapy were investigated. The results in Figure 6 show that, PS-MCM significantly increased cell proliferation of EL-4 T cells when compared with the blank group, and $2.5 \mu \mathrm{M}$ of doxorubicin markedly suppressed cell viability, whereas PS-MCM attenuated doxorubicin-induced toxic effects in EL-4 T cells.
Effects of PS-MCM on immune regulation in doxorubicin-treated EL-4 T cells

The levels of IFN-gamma and IL-4 were detected after treating with PS-MCM or/and doxorubicin in EL-4 T cells. Results in Table 2, show $250 \mu \mathrm{g} / \mathrm{mL}$ of PS-MCM treatment increased the production of cytokines in EL-4 T cells when compared to the blank group, whereas doxorubicin treatment did not affect the level of cytokines in EL-4 cells. With increasing dosage, PS-MCM potentially promoted the immune-stimulatory activity for the production of IFN-gamma and IL-4 in doxorubicin-treated EL-4 T cells.

\section{Discussion}

THP-1 cells have been extensively used to study func- 
tion, mechanism, signaling pathways and nutrient or drug transport of monocytes/macrophages. ${ }^{22}$ THP-1 cells can accurately mimic human monocytes and can differentiate into macrophages if properly incubated with the appropriate stimuli. ${ }^{23,24}$ Due to their uniform genetic background, THP-1 cells are frequently used as a model system for the study of monocytes abolishing donor variability. ${ }^{25}$ This cell line has also been employed to study cardiovascular diseases, ${ }^{24}$ for dermatological tests of new cosmetics, ${ }^{26}$ and toanalyze the effect of food-derived products in the immune response. ${ }^{23}$ Our data showed that PS-MCM exertedan M1-like induction in monocytes, inducing cytokines production such as IL-1beta and IFN-gamma (Table 1), and attenuated cytotoxic effects caused by chemotherapeutic drug doxorubicin in monocytes (Figure 1; Figure 2; Figure 3). Recently, polysaccharides have been reported to display immune stimulatory effects via inducing cytokines production in THP-1 monocytes. ${ }^{27,28}$ Cytokines IL-1beta, TNF-alpha, and IFN-gamma have been found to act as immune regulators and suppress cancer cells. ${ }^{29,30}$ Dox can cause a severe decrease in the number of white blood cells, red blood cells, and platelets in cancer patients. The accumulation of Dox in white blood cells has been investigated, and this accumulation in monocytes was greater than granulocytes and lymphocytes, suggesting that Dox resulted in cytotoxic effects and immune-suppression in monocytes. ${ }^{31}$ Taken together, our results suggest that PSMCM has potential to be used as a novel agent for immunotherapy in cancer patients by up-regulating monocytes survival and cytokines secretion.

$T$ cells encounter an antigen on antigen presentingcells (APCs), they can develop into at least two distinct T helper (Th) type cells: (1) Th1 cells that secrete IL-2, IFN-gamma, TNF-alpha; and (2) Th2 cells that secrete IL-4, IL-5, andIL-13. ${ }^{32}$ In the present study, doxorubicin treatment resulted in cytotoxicity of EL-4 T cells, whereas the negative effects of doxorubicin were blocked by PS-MCM treatment in EL-4 T cells. Moreover, IFN-gamma level was markedly increased in EL-4 cells after treating with PS-MCM, which is an indicator for activation of $\mathrm{T}$ cells, while there were no significant change in IL-4 levels of PS-MCM-treated EL-4 cells. The results indicated that PS-MCM elevated immune activity of EL-4 T cells as well as THP-1 monocytes against side effects in chemotherapy.
Recently, several searchers have investigated the regulatory potential of polysaccharides isolated from C. militaris, including Luo et al who suggested that two polysaccharide fractions by water extraction significantly promoted proliferation of lymphatic spleen cell in mice ${ }^{16}$. Another polysaccharide (CMPB90-1) was isolated from C. militaris by alkaline extraction, showing that this polysaccharide is composed of $(1 \rightarrow 6)$-linked $\alpha$-d-glucopyranosyl and $(1 \rightarrow 3)$-linked $\alpha$-d-glucopyranosyl residues ${ }^{33}$. In this study, CMPB90-1 has been found to be associated with proliferation of spleenic lymphocytes, enhanced cytoxicity of NK cells, and up-regulated T cell subpopulation. ${ }^{33}$ Moreover, the content of beta-glucan in polysaccharide isolated from C. militaris fermented with Pediococcus pentosaceus has been measured, and the polysaccharides exerted immune-enhancing activity in the CY-induced immunosuppressed mice. ${ }^{34}$ In addition to immune-stimulation, the $C$. militaris-derived polysaccharides also showed the anti-tumor and anti-fatigue potentials. ${ }^{35,36}$ Taken together, immunotherapy is the "treatment of disease by inducing, enhancing, or suppressing an immune response. ${ }^{33}$ Chemotherapy is a type of cancer treatment that uses chemo-drugs to kill cancer cells. As cancer cells divide more quickly than healthy cells, chemotherapeutic drugs effectively target those cells. Fast growing, normal cells such as monocytes and T cells, may also be damaged by chemo-drugs. Due to negative immune regulation, chemotherapeutic drugs have different side effects such as fatigue and disgusting. Therefore, functional foods supplements toregulate immune function may abolish or attenuate these side effects.

\section{Conclusion}

Here we found that PS-MCM increased the cell proliferations of monocytes and $\mathrm{T}$ cells and promoted immune activity through cytokines regulation. It is considered that PS-MCM could be developed as functional foods for attenuating side effects in cancer patients with chemotherapy.

\section{Conflict of interest}

The authors declare that there are no conflicts of interest regarding the publication of this paper.

\section{Funding}

This research work and subsidiary spending were sup- 
ported by the Taipei Medical University Hospital and Taipei Medical University (TMU-TMUH-105-03) (Taiwan, R.O.C.).

\section{References}

1. Sharifi N, Ozgoli S, Ramezani A. Multiple model predictive control for optimal drug administration of mixed immunotherapy and chemotherapy of tumours. Comput Meth Prog Biomed. 2017; 144:13-19. DOI:10.1016/j. cmpb.2017.03.012

2. Ernst E, Cassileth BR. The prevalence of complementary/alternative medicine in cancer: a systematic review. Cancer. 1998; 83(4):777-782.

3. Patterson RE, Neuhouser ML, Hedderson MM, Schwartz SM, Standish LJ, Bowen DJ, Marshall LM. Types of alternative medicine used by patients with breast, colon, or prostate cancer: predictors, motives, and costs. J Alternat Compl Med. 2002; 8(4):477-485. DOI: 10.1089/107555302760253676

4. Richardson MA, Sanders T, Palmer A, Greisinger A, Singletary SE. Complementary/alternative medicine use in a comprehensive cancer center and the implications for oncology. J Clin Oncol. 2000; 18(13):2505-2514. DOI: 10.1200/JCO.2000.18.13.2505

5. Xu W, Towers AD, Li P, Collet JP. Traditional Chinese medicine in cancer care: perspectives and experiences of patients and professionals in China. Eur Cancer Care. 2006; 15(4): 397-403. DOI: 10.1111/j.1365-2354.2006.00685.x 6. Qi F, Li A, Inagaki Y, Gao J, Li J, Kokudo N, Tang W. Chinese herbal medicines as adjuvant treatment during chemo- or radio-therapy for cancer. Biosci Trends. 2010; 4(6):297-307.

7. Youns M, Hoheisel JD, Efferth T. Traditional Chinese Medicines (TCMs) for molecular targeted therapies of tumors. Curr Drug Disc Technol. 2010; 7(1): 37-45. DOI:10.2174/157016310791162730

8. Yoshikaw N, Nakamura K, Yamaguchi Y, Kagota S, Shinozuka K, Kunitomo M. Antitumour activity of cordycepin in mice. Clin Exp Pharmacol Physiol. 2004; 31: S51-S53. DOI: 10.1111/j.1440-1681.2004.04108.x

9. Wehbe-Janek H, Shi Q, Kearney CM. Cordycepin/hydroxyurea synergy allows low dosage efficacy of cordycepin in MOLT-4 leukemia cells. Anticancer Res. 2007; 27(5A):3143-3146.

10. Chen Y, Chen YC, Lin YT, Huang SH, Wang SM. Cordycepin induces apoptosis of CGTH W-2 thyroid carcinoma cells through the calcium-calpain-caspase 7-PARP pathway. J Agric Food Chem. 2010; 58(22):1164511652. DOI:10.1021/jf1028976

11. Xu HL, Zhang LJ, Shi H, Zhu X, He X. Effects of cordycepin on Hep G2 and EA.hy926 cells: Potential antiproliferative, antimetastatic and anti-angiogenic effects on hepatocellular carcinoma. Oncol Lett. 2014; 7(5): 15561562. DOI: doi.org/10.3892/ol.2014.1965

12. Yamamoto K, Shichiri H, Uda A, Yamashita K, Nishioka T, Kume M, Makimoto H, Nakagawa T, Hirano T, Hirai M. Apoptotic effects of the extracts of Cordyceps militaris via Erk phosphorylation in a renal cell carcinoma cells line. Phytother Res. 2015; 29(5): 707-713. DOI: 10.1002/ptr.5305

13. Li G, Nakagome I, Hirono S, Itoh T, Fujiwara R. Inhibition of adenosine deaminase (ADA)-mediated metabolism of cordycepin by natural substances. Pharmacol Res Perspect. 2015; 3(2): e00121. DOI: 10.1002/prp2.121

14. Lin LT, Lai YJ, Wu SC, Hsu WH, Tai CJ. Optimal conditions for cordycepin production in surface liquid-cultured Cordyceps militaris treated with porcine liver extracts for suppression of oral cancer. J Food Drug Anal. 2018; 26(1): 135-144. DOI: 10.1016/j.jfda.2016.11.021

15. Liu XC, Zhu ZY, Tang YL, Wang MF, Wang Z, Liu AJ, Zhang YM. Structural properties of polysaccharides from cultivated fruit bodies and mycelium of Cordyceps militaris. Carbohydr Polymers. 2016; 142, 63-72. DOI: 10.1016/j.carbpol.2016.01.040

16. Luo X, Duan Y, Yang W, Zhang H, Li C, Zhang J. Structural elucidation and immunostimulatory activity of polysaccharide isolated by subcritical water extraction from Cordyceps militaris. Carbohydr Polymers, 2017; 157:794802. DOI: 10.1016/j.carbpol.2016.10.066.

17. Zitvogel L, Apetoh L, Ghiringhelli F, Kroemer G. Immunological aspects of cancer chemotherapy. Nat Rev Immunol. 2008; 8(1): 59-73. DOI: 10.1038/nri2216

18. Stewart TJ, Smyth MJ. Improving cancer immunotherapy by targeting tumor-induced immune suppression. Cancer Metast Rev. 2011; 30(1): 125-140. DOI:10.1007/ s10555-011-9280-5.

19. Garci Oliveira LP, Conte FL, de Oliveira Cardoso E, Conti BJ, Santiago KB, de Assis Golim M, Sforcin JM. Immunomodulatory/inflammatory effects of geopropolis produced by Meliponafa sciculata Smith in combination with doxorubicin on THP-1 cells. J Pharma Pharmacol. 2016; 68(12):1551-1558. DOI: 10.1111/jphp.12649 
20. Hsu WH, Lee BH, Liao TH, Hsu YW, Pan TM. Monascus-fermented metabolite monascin suppresses inflammation via PPAR-gamma regulation and JNK inactivation in THP-1 monocytes. Food Chem Toxicol. 2012; 50(5):1178-1186. DOI: 10.1016/j.fct.2012.02.029.

21. Hsu WH, Lee BH, Hsu YW, Pan TM. Inhibition of Th2 cytokine production in T cells by monascin via PPARgamma activation. J Agric Food Chem. 2013; 61(34):81268133. DOI: $10.1021 /$ jf402373z

22. Chanput W, Mes JJ, Wichers HJ. THP-1 cell line: an in vitro cell model for immunemodulation approach. Int Immuno pharmacol. 2014; 23(1): 37-45.

23. Chanput W, Mes J, Vreeburg RA, Savelkoul HF, Wichers HJ. Transcription profiles of LPS-stimulated THP-1 monocytes and macrophages: a tool to study inflammation modulating effects of food derived compounds. Food Funct. 2010; 1(3): 254-261. DOI: 10.1016/j. intimp.2014.08.002

24. Qin Z. The use of THP-1 cells as a model for mimicking the function and regulation of monocytes and macrophages in the vasculature. Atherosclerosis. 2012; 221(1): 2-11. DOI: 10.1016/j.atherosclerosis.2011.09.003.

25. Schildberger A, Rossmanith E, Eichhorn T, Strassi K, Weber V. Monocytes, peripheral blood mononuclear cells,and THP-1 cells exhibit different cytokine expression patterns following stimulation with lipopolysaccharide. Mediat Inflam, 2013; 2013(2013): 697972. DOI: 10.1155/2013/697972

26. Garcia I, Pouzet C, Brulase M, Bauza E, Botto JM, Domlge N. Evaluation of THP-1cell line as an in vitro model for long-term safety assessment of new molecules. Int J CosmSci. 2013; 35(6): 568-574. DOI: 10.1111/ ics. 12078

27. Wu SC, Lee BH. Buckwheat polysaccharide exerts antiproliferative effects in THP-1 human leukemia cells by inducing differentiation. J Med Food. 2011; 14(1-2):26-33. DOI: $10.1089 /$ jmf.2010.1252.

28. Lee BH, Hsu WH, Liao TH, Pan TM. Inhibition of leukemia proliferation by a novel polysaccharide identi- fied from Monascus-fermented dioscorea via inducing differentiation. Food Funct. 2012; 3(7):758-764. DOI: $10.1039 / \mathrm{c} 2 \mathrm{fo} 30026 \mathrm{e}$

29. Taburee P, Siripin D, Wongjindanon N, Fucharoen S, Tanyong DI. Interleukin-1beta and tumor necrosis factor-alpha induced apoptosis via caspase in leukemic K562 and HL-60 cell lines. Songklanakarin J Sci Technol. 2011; 33(5):487-492.

30. Wall L, Burke F, Barton C, Smyth J, Balkwill F. INF-gamma induces apoptosis in ovarian cancer cells in vivo and in vitro. Clin Cancer Res. 2003; 9(7):2487-2496.

31. Morjani H, Pignon B, Millot JM, Debal V, Lamiable D, Potron G, Etienne JC, Manfait M. Intranuclear concentration measurements of doxorubicin in living leucocytes from patients treated for a lympho-proiferative disorder. Leuk Res. 1992; 16(6-7):647-653.

32. Neurath MF, Finotto S, Glimcher LH. The role of Th1/Th2polarization in mucosal immunity. Nat Med. 2002; 8(6): 567-573. DOI: 10.1038/nm0602-567

33. Bi S, Jing Y, Zhou Q, Hu X, Zhu J, Guo Z, Song L, Yu R. Structural elucidation and immunostimulatory activity of a new polysaccharide from Cordyceps militaris. Food Funct. 2018; 9(1): 279-293. DOI: 10.1039/c7fo01147d.

34. Kwon HK, Jo WR, Park HJ. Immune-enhancing activity of $C$. militaris fermented with Pediococcus pentosaceus (GRC-ON89A) in CY-induced immunosuppressed model. BMC Complement. Altern. Med. 2018; 18(1):75. DOI: 10.1186/s12906-018-2133-9.

35. Liu F, Zhu ZY, Sun X, Gao H, Zhang YM. The preparation of three selenium-containing Cordyceps militaris polysaccharides: Characterization and anti-tumor activities. Int. J. Biol Macromol. 2017; 99:196-204. DOI: 10.1016/j.ijbiomac.2017.02.064

36. Xu YF. Effect of polysaccharide from Cordyceps militaris (Ascomycetes) on physical fatigue induced by forced swimming. Int. J. Med. Mushrooms. 2016; 18(12): 10831092. DOI: 10.1615/IntJMedMushrooms.v18.i12.30

37. Guo B, Fu S, Zhang J, Liu B, Li Z. Targeting inflammasome/IL-1 pathways for cancer immunotherapy. Sci Rep. 2017; 6:36107. DOI: 10.1038/srep36107. 